\title{
Correlation between Cancer Breast Subtypes and Age at Presentation in Egyptian Patients; Single Institution Experience
}

\author{
Azza M. Adel*, Dalia Abdelghani \\ Department of Clinical Oncology, Faculty of Medicine, Ain Shams University, Cairo, Egypt \\ Email: *azzaelkhateeb@gmail.com
}

How to cite this paper: Adel, A.M. and Abdelghani, D. (2020) Correlation between Cancer Breast Subtypes and Age at Presentation in Egyptian Patients; Single Institution Experience. Journal of Cancer Therapy, 11, 26-34.

https://doi.org/10.4236/jct.2020.111003

Received: December 11, 2019

Accepted: January 13, 2020

Published: January 16, 2020

Copyright $\odot 2020$ by author(s) and Scientific Research Publishing Inc. This work is licensed under the Creative Commons Attribution-NonCommercial International License (CC BY-NC 4.0). http://creativecommons.org/licenses/by-nc/4.0/ (c) (i) (8) Open Access

\begin{abstract}
Background: Breast cancer is defined according to molecular subtypes. Each molecular subtype defines different disease behavior and requires different treatment. The different molecular subtypes have different risk factors and different distribution across age classes. Aim of the study: To detect the incidence of cancer breast subtypes by age among Egyptian patients treated at the Clinical Oncology Department, Faculty of Medicine, Ain Shams University, in the period between April 2016 and December 2018. Patients and Methods: Inclusion criteria: Cases with proven pathological diagnosis and underwent IHC studies for the molecular subtype while exclusion criteria were: Bilateral cases, cases with unknown molecular subtype or age at presentation, cases with multiple primaries, cases with in situ cancer, male breast cancer cases, and cases diagnosed during pregnancy. Age classes were computed in four groups: from $20-35,>35-50,>50-65$ and those older than 65 years of age. Immunohistochemical studies were done; ER, PR and HER2 were recorded for each case, Molecular subtypes were defined as follows: HR+/HER2-, HR+/HER2+, HER2 overexpressed (HER2 positive, HR-) and Triple Negative Breast Cancer; TNBC (HER2 negative, ER negative and PR negative). Results: one thousand and two cases were included in the study. The median age was 51 years and the mean age was $51.64 \pm 11.74$, with range from 24 to 85 years. The total number of ER positive patients was 706 patients (70.5\%), the total number of PR positive patients was 667 (66.6\%), and the total number of Her2 positive patients was 286 patients (28.5\%). While there were no statistically significant differences in the incidence of ER and PR positivity among all age classes, Her2 over expression decreased with age and the difference was statistically significant (P-value: 0.012 ). Her2 overexpression subtype incidence decreased by age and it was highest in the younger age group $17.6 \%$ compared to $8.2 \%$ in the older age group and the difference was statistically significant. Similarly,
\end{abstract}


HR+/HER2 - tumors incidence were higher in patients older than 65 (57.4\%) and lower in the younger age group (40.5\%) (P-value: 0.031 ). Triple negative tumors incidence ranged from $14.9 \%$ for those younger than 35 to $17.2 \%$ for those older than 65 years. Conclusion: This study shows that there are significant differences in the age distribution by molecular subtype and the incidence of Her 2 overexpression subtype decreases by age. The study also shows that the nature of the breast cancer in the group of Egyptian patients studied is more of the favorable hormonal positive subtype.

\section{Keywords}

Breast Cancer, Molecular Subtypes, Egyptian, Age

\section{Introduction}

Breast cancer is the most frequent cancer in women worldwide and though incidence rates are lower in Africa compared to the rest of the world, mortality is high [1] [2] [3]. In Egypt, breast Cancer represented 38.8\% of cases in 2007 [4].

Every patient should undergo prognostic factors analysis among which the most important are, Estrogen Receptor (ER), Progesterone Receptor (PR), Human epidermal growth factor receptor (Her2/neu) [5]. Each of these parameters shares in the determination of tumor behavior and accordingly is treated in a different way [6]. Hormonal receptors (HRs) are also a fundamental characteristic of the epidemiology of this malignancy [7] and those tumors have better prognosis and are responsive to hormonal therapy [8]. Accordingly, breast cancer is defined according to molecular subtypes [9]. These molecular subtypes are identified by immunohistochemical studies which became an essential assessment tool [10]. Recurrence in terms of progression free survival and site of recurrence is affected by the molecular subtype, and each of them has different risk factors, and different distribution across age classes [11]. Some studies showed that the proportion of luminal A subtype increased with age, whereas triple negative tumors decreased with age [12]. Analysis of molecular subtypes is important to evaluate and compare survival of patients and plane resources for treatment [13].

Whether genetic and racial factors are controlling prevalence of molecular subtypes is an open question. It was reported that; $79 \%$ of breast cancer in white American women are ER+, while the percentage is lower among black Americans (about 61\%) [14] [15]. Some studies [16] [17] reported higher proportion of basal-like subtype in African patients, while others suggest that it is not different from that reported worldwide [18] [19].

\section{Aim of the study:}

To detect the incidence of cancer breast subtypes by age among Egyptian patients treated at the Clinical Oncology Department, Faculty of Medicine, Ain 
Shams University, in the period between April 2016 and December 2018.

\section{Patients and Methods}

This retrospective study was carried out by comprehensive review of the files of cases of cancer breast treated at the clinical oncology department, Faculty of Medicine, Ain Shams University, in the period between April 2016 and December 2018 regarding age of the patients and their molecular subtypes.

Inclusion criteria were: Cases with proven pathological diagnosis and underwent IHC studies for the molecular subtype while exclusion criteria were: Bilateral cases, cases with unknown molecular subtype or age at presentation, cases with multiple primaries, cases with in situ cancer, male breast cancer cases, and cases diagnosed during pregnancy.

Age classes were computed in four groups: from $20-35,>35-50,>50-65$ and those older than 65 years of age. Immunohistochemical data namely; Estrogen receptor (ER), progesterone receptor (PR) and human epidermal growth factor receptor (HER2) were recorded for each case. Ki 67 being not routinely performed for the patients was not included in the classification. Analysis included only cases confirmed to be Her2/neu positive by FISH or SISH as per the routine laboratory studies of the breast unit at our institute.

Molecular subtypes were defined as follows: HR+/HER2-, HR+/HER2+, HER2+ overexpressed (HER2 positive, HR-) and Triple Negative Breast Cancer; TNBC (HER2 negative, ER negative and PR negative), HR was considered positive if any of ER or PR were found to be positive as per the guidelines of the breast clinic.

\section{Statistical Analysis}

Data were collected, revised, coded and entered to the Statistical Package for Social Science (IBM SPSS) version 23. Quantitative data were presented as mean, standard deviations, median with inter-quartile range (IQR) and range while qualitative variables were presented as number and percentages. The comparison between groups with qualitative data was done by using Chi-square test. The confidence interval was set to $95 \%$ and the margin of error accepted was set to $5 \%$. So, the P-value was considered significant at the level of $<0.05$.

\section{Results}

In the allocated period 1636 cases were recorded in the files among whom 634 cases were excluded as per the exclusion criteria of the study and 1002 cases were included in the study. The median age was 51 years and the mean age was 51.64 \pm 11.74 , with range from 24 to 85 years (Table 1 ).

The total number of patients below 35 years of age was $74(7.4 \%)$ patients while those more than 65 years of age were 244 patients (24.4\%). In the whole study group the total number of ER positive patients were 706 patients (70.5\%) and the total number of PR positive patients were 667 (66.6\%), the total number of Her2 positive patients were 286 patients (28.5\%) (Table 2). 
Table 1. Mean and Median age of patients included in the study.

\begin{tabular}{cc}
\hline Age & Total No. $=1002$ \\
\hline Median (IQR) & $51(43-60)$ \\
Mean \pm SD & $51.64 \pm 11.74$ \\
Range & $24-85$ \\
\hline
\end{tabular}

Table 2. Correlation between age groups and IHC data of the patients.

\begin{tabular}{|c|c|c|c|c|c|c|c|c|c|}
\hline & & \multicolumn{4}{|c|}{ Age groups } & \multirow{3}{*}{$\begin{array}{c}\text { Total } \\
\text { No (\%) }\end{array}$} & \multirow{2}{*}{\multicolumn{3}{|c|}{ Chi-square test }} \\
\hline & & \multirow{2}{*}{$\begin{array}{l}(20-35) \\
\text { No. (\%) }\end{array}$} & \multirow{2}{*}{$\begin{array}{l}(35-50) \\
\text { No. (\%) }\end{array}$} & \multirow{2}{*}{$\begin{array}{l}(51-65) \\
\text { No. (\%) }\end{array}$} & \multirow{2}{*}{$\begin{array}{c}>65 \\
\text { No. (\%) }\end{array}$} & & & & \\
\hline & & & & & & & $x^{2}$ & $\mathrm{P}$-value & Sig. \\
\hline & Negative & $25(33.8 \%)$ & $92(26.7 \%)$ & $114(33.6 \%)$ & $65(26.6 \%)$ & $296(29.5 \%)$ & & & \\
\hline ER & Positive & 49 (66.2\%) & $253(73.3 \%)$ & $225(66.4 \%)$ & $179(73.4 \%)$ & $706(70.5 \%)$ & 5.717 & 0.126 & NS \\
\hline & Total & $74(7.4 \%)$ & $345(34.4 \%)$ & $339(33.8)$ & $244(24.4 \%)$ & $1002(100 \%)$ & & & \\
\hline & Negative & 31 (41.9\%) & $101(29.3 \%)$ & $122(36.0 \%)$ & $81(33.2 \%)$ & 335 (33.4) & & & \\
\hline PR & Positive & $43(58.1 \%)$ & $244(70.7 \%)$ & $217(64.0 \%)$ & $163(66.8 \%)$ & $667(66.6)$ & 6.059 & 0.109 & NS \\
\hline & Total & $74(7.4 \%)$ & $345(34.4 \%$ & $339(33.8 \%)$ & $244(24.4 \%)$ & $1002(100 \%)$ & & & \\
\hline & Negative & $41(55.4 \%)$ & $249(72.2 \%)$ & $243(71.7 \%)$ & $183(75.0 \%)$ & $716(71.5 \%)$ & & & \\
\hline HER2 & Positive & 33 (44.6\%) & $96(27.8 \%)$ & $96(28.3 \%)$ & $61(25.0 \%)$ & $286(28.5 \%)$ & 10.945 & 0.012 & $S$ \\
\hline & Total & $74(7.4 \%)$ & 345 (34.4\%) & $339(33.8 \%)$ & 244 (24.4\%) & $1002(100 \%)$ & & & \\
\hline
\end{tabular}

ER: Estrogen Receptor, PR: Progesterone Receptor, HER2: Human Epidermal Growth Factor Receptor, NS: not significant, S: significant.

While there were no statistically significant difference in the incidence of ER and $\mathrm{PR}$ positivity among all age classes, Her2 over expression decreased with age and the difference was statistically significant (P-value: 0.012) (Table 2 and Figure 1).

Regarding distribution of molecular subtypes by different age groups (Table 3 and Figure 2), there was a statistically significant difference (P-value: 0.031 ), as Her2 overexpression subtype incidence decreased by age (17.6\% compared to $8.2 \%$ in the younger and older age groups respectively) and $\mathrm{HR}+/ \mathrm{Her}+$ were also higher in the younger age group $27 \%$ compared to $17.2 \%$ in both groups respectively. Meanwhile, HR+/HER2- tumors incidence were higher in patients older than 65 (57.4\%) and lower in the younger age group (40.5\%). Regarding the TNBC the incidence ranged from $14.9 \%$ for those younger than 35 to $17.2 \%$ for those older than 65 years.

\section{Discussion}

The current study aimed at exploring the patterns of molecular subtypes and its age distribution among patients treated at our department, and though seems to be easy information to get, there is actually no enough studies to answer the question what is the actual age distribution of Egyptian breast cancer patients as defined by molecular subtypes and whether there is a specific molecular subtype that is more prevalent among those patients. 
Table 3. Correlation between age and molecular subtypes of the patients.

\begin{tabular}{|c|c|c|c|c|c|c|c|c|}
\hline \multirow{2}{*}{$\begin{array}{l}\text { Molecular } \\
\text { subtype }\end{array}$} & \multirow{2}{*}{$\begin{array}{l}(20-35) \\
\text { No. (\%) }\end{array}$} & \multirow{2}{*}{$\begin{array}{l}(35-50) \\
\text { No. (\%) }\end{array}$} & \multirow{2}{*}{$\begin{array}{l}(51-65) \\
\text { No. (\%) }\end{array}$} & \multirow{2}{*}{$\begin{array}{c}>65 \\
\text { No. (\%) }\end{array}$} & \multirow{2}{*}{$\begin{array}{c}\text { total } \\
\text { No (\%) }\end{array}$} & \multicolumn{3}{|c|}{ Chi-square test } \\
\hline & & & & & & $x^{2}$ & P-value & Sig. \\
\hline $\mathrm{HR}+/ \mathrm{Her}-$ & $30(40.5 \%)$ & 189 (54.8\%) & $187(55.2 \%)$ & $140(57.4 \%)$ & $546(54.5 \%)$ & & & \\
\hline $\mathrm{HR}+/ \mathrm{Her}+$ & $20(27.0 \%)$ & $70(20.3 \%)$ & $51(15.0 \%)$ & $42(17.2 \%)$ & $183(18.3 \%)$ & & & \\
\hline HER2 & $13(17.6 \%)$ & $27(7.8 \%)$ & $44(13.0 \%)$ & $20(8.2 \%)$ & $104(10.3 \%)$ & 18.391 & 0.031 & S \\
\hline TNBC & $11(14.9 \%)$ & $59(17.1 \%)$ & $57(16.8 \%)$ & $42(17.2 \%)$ & $169(16.9 \%)$ & & & \\
\hline Total & $74(7.4)$ & 345 (34.4) & $339(33.8)$ & $244(22.4)$ & $1002(100 \%)$ & & & \\
\hline
\end{tabular}

HR+/HER2- (HR positive, HER2 negative), HR+/HER2 + (HR positive, HER2 positive), HER2+ overexpressed (HR negative, HER2 positive) and Triple Negative Breast Cancer; TNBC (HR negative, HER2 negative), S: Significant.

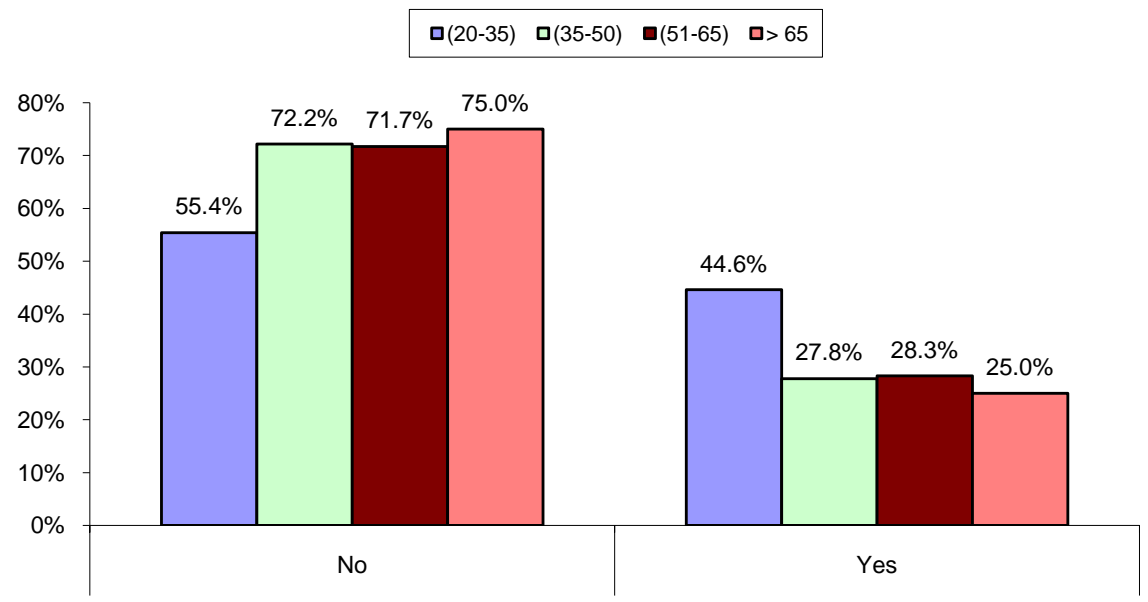

Figure 1. Percentage of Her2 over expression in the studied patients.

$$
\mathbf{\square}(20-35) \square(35-50) \quad \mathbf{a}(51-65) \quad \square>65
$$

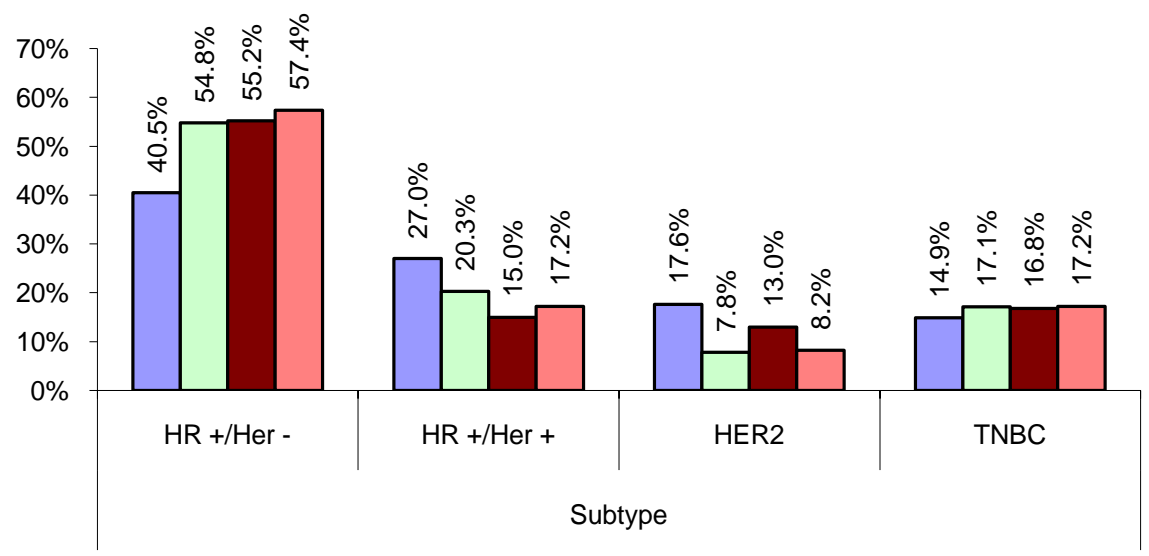

Figure 2. Distribution of molecular subtypes by age class.

The median age of patients was 51 years with an IQR $(43-60)$ and the mean was 51 years which goes in accordance with that reported in other studies on Egyptian patients that reported a mean age of 53 years and a median of 52 years 
in one study of 263 patients [20], and a mean age of 51.3 years in another one [21]. However, lower Median age of 46 years was reported in Hospital-based reports of The National Cancer Institute of Egypt [22]. In Egypt, though some reports suggest age distribution shift towards early sixties, median age at diagnosis is believed to be younger than that reported in Western data [22] [23] [24]. Regarding the Arab countries, a comprehensive literature review of reports of breast cancer in Arab countries, reported on an average age of 48 with a range of 43 52 years and a median of 48.5 years [23].

In the current study ER+ tumors dominated with an incidence of $70.4 \%$ followed by PR+ tumors with $66.5 \%$ incidence compared to $65 \%$ and $43 \%$ respectively for another report of Egyptian patients [21]. Gharbia cancer registry in Egypt reported an incidence of $69 \% \mathrm{HR}+$ in all cases with known receptor status [25]. Regarding other countries, lower incidence of $51.5 \%$ HR positive tumors was reported in 194 Tunisian patients with breast cancer [26]. It was also reported that, luminal subtype was predominant in African post-menopausal North Americans [21] [27]. Additionally, luminal subtype was also predominant in those of Sudanese and Tunisian descent [26].

The incidence of Her2 positive tumors in the current study was $28.5 \%$ but this figure has to take into consideration that our institute is a referral center for the targeted therapy trastuzumab so though our results were in accordance with Salhia et al. [21] who reported on an incidence of $25.1 \%$, it was different from Hussein et al. who reported on an incidence as low as $14.1 \%$ [20].

In the current study there was a statistically significant difference in distribution of molecular subtypes by age (P-value: 0.031 ), so though Hormonal positive tumors (luminal subtype) in general was the predominant subtype among all age groups, $\mathrm{HR}+/ \mathrm{Her}+$ were higher in the younger age group (27\% compared to $17.2 \%$ ) and Her2 overexpression subtype was higher in the younger age group (17.6\% compared to $8.2 \%$ ). Triple negative tumors had the incidence of $16.7 \%$ in the current study compared to $19.0 \%$ reported by Hussein et al. [20], and $28.5 \%$ in a report of Elhawary et al. who reported on 274 surgical specimens [28]. High frequency of the basal-like subtype has been reported in about $40 \%$ of young premenopausal African North American women [29].

It was also reported that triple negative tumors decreased with age [12]. This finding was neither supported in the current study nor by Cortet et al. [13]. In the current study, the distribution of the TNBC was consistent among all age classes which suggest that the nature of the disease in the Egyptian patients could be the same as that reported elsewhere.

This study was limited by the fact that there is no cancer patients' registry in Egypt and the measurement of Ki 67 is not done routinely for patients in our department so the luminal subtype could not be further subdivided in most of the cases.

\section{Conclusion}

This study shows that there are significant differences in the age distribution by 
molecular subtype and the incidence of Her2 overexpression subtype decreases by age while the incidence of TNBC is consistent among all age classes. The study also shows that the nature of the breast cancer in the group of Egyptian patients studied is more of the favorable hormonal positive luminal subtype and the more aggressive triple negative subtype is not of higher incidence compared to other reports worldwide.

\section{Ethics approval}

The authors made the necessary regulatory arrangements to use the data from patients' records.

\section{Conflicts of Interest}

The authors declare no conflicts of interest regarding the publication of this paper.

\section{References}

[1] GLOBOCAN: Estimated Cancer Incidence, Mortality and Prevalence Worldwide in 2012. http://globocan.iarc.fr/Pages/summary_table_pop_sel.aspx

[2] International Agency for Research on Cancer (2012) GLOBOCAN 2012.

[3] Eng, A., Mc Cormack, V. and dos-Santos-Silva, I. (2014) Receptor-Defined Subtypes of Breast Cancer in Indigenous Populations in Africa: Systematic Review and Meta-Analysis. PLOS Medicine, 11, e1001720. https://doi.org/10.1371/journal.pmed.1001720

[4] Gabr, A., Razek, K., Atta, H., et al. (2014) Demographic Characteristics and Clinicopathological Presentation of Breast Cancer Patients in South Egypt Cancer Institute (2005-2012). AAMJ, 12, 310-321.

[5] Bagaria, S.P., Ray, P.S., et al. (2014) Personalizing Breast Cancer Staging by the Inclusion of ER, PR, and HER2. JAMA Surgery, 149, 125-129.

https://doi.org/10.1001/jamasurg.2013.3181

[6] Kondov, B., Milenkovikj, Z., Kondov, G., et al. (2018) Presentation of the Molecular Subtypes of Breast Cancer Detected by Immunohistochemistry in Surgically Treated Patients. Open Access Macedonian Journal of Medical Sciences, 6, 961-967. https://doi.org/10.3889/oamjms.2018.231

[7] Yang, X.R., Chang-Claude, J., Goode, E.L., et al. (2011) Associations of Breast Cancer Risk Factors with Tumor Subtypes: A Pooled Analysis from the Breast Cancer Association Consortium Studies. Journal of the National Cancer Institute, 103, 250-263. https://doi.org/10.1093/jnci/djq526

[8] Davies, C., Godwin, J., Gray, R., et al. (2011) Relevance of Breast Cancer Hormone Receptors and Other Factors to the Efficacy of Adjuvant Tamoxifen: Patient-Level Meta-Analysis of Randomised Trials. The Lancet, 378, 771-784. https://doi.org/10.1016/S0140-6736(11)60993-8

[9] Perou, C.M., Sorlie, T., Eisen, M.B., et al. (2000) Molecular Portraits of Human Breast Tumours. Nature, 406, 747-752. https://doi.org/10.1038/35021093

[10] Prat, A., Carey, L.A., Adamo, B., et al. (2014) Molecular Features and Survival Outcomes of the Intrinsic Subtypes within HER2-Positive Breast Cancer. Journal of the National Cancer Institute, 106, pii: dju152. https://doi.org/10.1093/jnci/dju152 
[11] Metzger-Filho, O., Sun, Z., Viale, G., et al. (2013) Patterns of Recurrence and Outcome According to Breast Cancer Subtypes in Lymph Node-Negative Disease: Results from International Breast Cancer Study Group Trials VIII and IX. Journal of Clinical Oncology: Official Journal of the American Society of Clinical Oncology, 31, 3083-3090. https://doi.org/10.1200/JCO.2012.46.1574

[12] Jenkins, E.O., Deal, A.M., Anders, C.K., et al. (2014) Age-Specific Changes in Intrinsic Breast Cancer Subtypes: A Focus on Older Women. Oncologist, 19, 1076-1083. https://doi.org/10.1634/theoncologist.2014-0184

[13] Cortet, M., Bertaut, A., Molinié, F., et al. (2018) Trends in Molecular Subtypes of Breast Cancer: Description of Incidence Rates between 2007 and 2012 from Three French Registries. BMC Cancer, 18, 161. https://doi.org/10.1186/s12885-018-4080-8

[14] Jemal, A. and Fedewa, S.A. (2012) Is the Prevalence of ER-Negative Breast Cancer in the US Higher among Africa-Born than US-Born Black Women? Breast Cancer Research and Treatment, 135, 867-873. https://doi.org/10.1007/s10549-012-2214-2

[15] Rennert, G. (2006) Cancer Incidence in Four Member Countries (Cyprus, Egypt, Israel and Jordan) of the Middle East Cancer Consortium (MECC) Compared with US SEER. National Cancer Institute, Bethesda, NIH Publication 06-5873.

[16] Bird, P.A., Hill, A.G. and Houssami, N. (2008) Poor Hormone Receptor Expression in East African Breast Cancer: Evidence of a Biologically Different Disease? Annals of Surgical Oncology, 15, 1983-1988. https://doi.org/10.1245/s10434-008-9900-7

[17] Huo, D., Ikpatt, F., Khramtsov, A., Dangou, J.M., Nanda, R., et al. (2009) Population Differences in Breast Cancer: Survey in Indigenous African Women Reveals Overrepresentation of Triple-Negative Breast Cancer. Journal of Clinical Oncology, 27, 4515-4521. https://doi.org/10.1200/JCO.2008.19.6873

[18] McCormack, V.A., Joffe, M., van den Berg, E., et al. (2013) Breast Cancer Receptor Status and Stage at Diagnosis in over 1,200 Consecutive Public Hospital Patients in Soweto, South Africa: A Case Series. Breast Cancer Research, 15, R84. https://doi.org/10.1186/bcr3478

[19] Adebamowo, C.A., Famooto, A., Ogundiran, T.O., et al. (2008) Immunohistochemical and Molecular Subtypes of Breast Cancer in Nigeria. Breast Cancer Research and Treatment, 110, 183-188. https://doi.org/10.1007/s10549-007-9694-5

[20] Hussein, Mosbah, M., Farouk, O., et al. (2013) Hormone Receptor and Age Distribution in Breast Cancer Patients at a University Hospital in Northern Egypt. Breast Cancer, 7, 51-57. https://doi.org/10.4137/BCBCR.S12214

[21] Salhia, B., Tapia, C., Ishak, E.A., et al. (2011) Molecular Subtype Analysis Determines the Association of Advanced Breast Cancer in Egypt with Favorable Biology. BMC Women's Health, 11, 44. https://doi.org/10.1186/1472-6874-11-44

[22] Omar, S., Khaled, H., Gaafar, R., et al. (2003) Breast Cancer in Egypt: A Review of Disease Presentation and Detection Strategies. Eastern Mediterranean Health Journal, 9, 448-463.

[23] Najjar, H. and Easson, A. (2010) Age at Diagnosis of Breast Cancer in Arab Nations. International Journal of Surgery, 8, 448-452. https://doi.org/10.1016/j.ijsu.2010.05.012

[24] El Saghir, N.S., Khalil, M.K., Eid, T., et al. (2007) Trends in Epidemiology and Management of Breast Cancer in Developing Arab Countries: A Literature and Registry Analysis. International Journal of Surgery, 5, 225-233.

https://doi.org/10.1016/j.ijsu.2006.06.015

[25] Dey, S., Soliman, A.S., Hablas, A., et al. (2010) Urban-Rural Differences in Breast Cancer Incidence in Egypt (1999-2006). Breast, 19, 417-423. 
https://doi.org/10.1016/j.breast.2010.04.005

[26] Ben Abdelkrim, S., Trabelsi, A., Missaoui, N., et al. (2010) Distribution of Molecular Breast Cancer Subtypes among Tunisian Women and Correlation with Histopathological Parameters: A Study of 194 Patients. Pathology-Research and Practice, 206, 772-775. https://doi.org/10.1016/j.prp.2010.07.012

[27] Awadelkarim, K.D., Arizzi, C., Elamin, E.O., et al. (2008) Pathological, Clinical and Prognostic Characteristics of Breast Cancer in Central Sudan versus Northern Italy: Implications for Breast Cancer in Africa. Histopathology, 52, 445-456. https://doi.org/10.1111/j.1365-2559.2008.02966.x

[28] El-Hawary, A.K., Abbas, A.S., Elsayed, A.A. and Zalata, K.R. (2012) Molecular Subtypes of Breast Carcinoma in Egyptian Women: Clinicopathological Features. Pathology-Research and Practice, 208, 382-386.

https://doi.org/10.1016/j.prp.2012.03.011

[29] Onitilo, A.A., Engel, J.M., Greenlee, R.T. and Mukesh, B.N. (2009) Breast Cancer Subtypes Based on ER/PR and Her2 Expression: Comparison of Clinicopathologic Features and Survival. Clinical Medicine \& Research, 7, 4-13.

https://doi.org/10.3121/cmr.2008.825 